\title{
Prognostic factors in patients with intracerebral haematoma
}

\author{
C L Franke, J C van Swieten, A Algra, J van Gijn
}

\begin{abstract}
In a prospective study, the prognostic value of clinical characteristics in 157 consecutive patients with spontaneous supratentorial intracerebral haemorrhage were examined by means of multivariate analysis.

Two days after the event 37 (24\%) patients had died. Factors independently contributing to the prediction of two day mortality were pineal gland displacement on CT of $3 \mathrm{~mm}$ or more (p $<0.001$ ), blood glucose level on admission of $8.0 \mathrm{mmol} / \mathrm{l}$ or more $(p=0.01)$, eye and motor score on the Glasgow Coma Scale of eight out of 10 or less $(p=0.022)$ and haematoma volume of $40 \mathrm{~cm}^{3}$ or more $(p=0.037)$. Between the third day and one year after the event another 46 of the 120 two day survivors had died; the independent prognostic indicators for death during that period were: age 70 years or more $(p<0.001)$ and severe handicap (Rankin grade five) on the third day $(p<0.001)$. Functional independence (Rankin grade two or less) at one year was most common not only with the converse features of age less than 70 years $(p<0.01)$ and Rankin grade four or less on the third day $(p=0.002)$, but also with an eye and motor score on the Glasgow Coma Scale of nine or 10 on the third day $(p<0.001)$.
\end{abstract}

The 120 patients with intracerebral haemorrhage who were still alive two days after the event were matched with 120 patients with cerebral infarction, according to age, level of consciousness on the third day after stroke (Glasgow Coma Scale) and handicap (Rankin grade). Survival and handicap after one year did not differ between these two groups. The conclusion drawn is that it is not the cause (intracerebral haemorrhage or cerebral infarction) but the extent of the brain lesion that determines the outcome in patients who survive the first two days.

$(\mathcal{F}$ Neurol Neurosurg Psychiatry 1992;55:653-657)

It is well known that patients with intracerebral haematoma (ICH) have a high death rate, especially in the first few days. ${ }^{1-5}$ Factors such as the score on the Glasgow Coma Scale (GCS), the size of the haematoma, age, rupture of the haemorrhage in the ventricular system, midline shift and pulse pressure have been identified as determinants of outcome in multivariate analysis. ${ }^{6-9}$ In contrast, the mortality from cerebral infarction (CI) is lower and usually occurs later than the first two days after stroke. ${ }^{10}$ Studies that compared outcome after ICH with that after CI generally mention a better prognosis for patients with $\mathrm{CI}^{15^{11-14}}$ Only one study found no significant difference in outcome after one year. ${ }^{15}$ All these studies compared consecutive groups of patients with ICH or CI, independent of age, level of consciousness or disability on admission.

In this prospective study, we analysed the short term (two days) and the long term prognosis of patients with supratentorial $\mathrm{ICH}$, and we also compared those patients with $\mathrm{ICH}$ who survived the first two days with a matched group of patients with $\mathrm{CI}$.

\section{Patients and methods}

We prospectively studied 157 consecutive patients with spontaneous supratentorial ICH who were admitted to the De Wever-Ziekenhuis in Heerlen $(n=96)$ and the University Hospital in Utrecht $(n=61)$, from October 1986 to September 1989. Their ages ranged from 33 to 91 years (mean 68 years); 89 patients were men (57\%). Patients where aneurysmal bleeding was suspected from the site of the haematoma were excluded. Ninetysix per cent of the patients were admitted to hospital within 24 hours after the haemorrhage and $75 \%$ within three hours. The eye and motor score on the GCS was used as a measure of the level of consciousness; the verbal score was not taken into account because many patients were unable to speak due to aphasia or because they were intubated. With this modification, the maximum on the GCS is 10 . The modified Rankin scale is a useful measure of handicap, particularly in the long term. ${ }^{16} 17$ For the assessment of outcome after one year, the Rankin scale was contracted into two categories: functionally independent (corresponding to grades zero, one or two) and functionally dependent (corresponding to grades three, four or five). The severity of the hemiparesis was estimated according to the Medical Research Council scale, in the most severely affected muscle groups and dichotomised in severe $(0-2)$ versus moderate to no hemiparesis or normal power (3-5). Blood glucose levels could be obtained in all but 19 patients. Motor power in deeply unconscious patients $(n=3)$ who could not respond to command or react on a painful stimulus was graded as severe hemiparesis. in revised form 8 Dece

Accepted 17 January 1992 
The diagnosis of $\mathrm{ICH}$ was confirmed by CT in 156 patients and by post mortem examination in one patient. The haematoma volumes were measured from the first CT scan, directly from the video screen or by means of the best fit method. ${ }^{18}$ Two neurologists assessed the CT scans according to site and volume of the haematoma, rupture into the ventricular system and midline shift. None of the patients was surgically treated.

The 120 patients who were still alive two days after ICH were matched with 120 patients with supratentorial CI. These patients had been admitted to the same hospitals and during the same period as the patients with ICH. Eighty nine per cent of the patients with CI had been admitted to hospital within 24 hours after stroke (54\% within three hours) All patients with $\mathrm{CI}$ were investigated by $\mathrm{CT}$. The patients were primarily matched according to Rankin grades, and as near as possible according to age (approximately 10 years) and according to the eye and motor score of the GCS (approximately 2) on the third day after stroke.

The sum of the GCS eye and motor score on the third day after stroke differed slightly between the two patient groups: 34 patients with ICH had a score of eight or less versus 23 CI patients. The frequency of definite stroke in the past, the use of oral anticoagulants or a history of peripheral vascular disease were similar in the two groups. Diabetes mellitus, a history of atrial fibrillation or a history of other heart disease were more frequent in the patients with CI. A systolic blood pressure on admission of more than $160 \mathrm{~mm} \mathrm{Hg}$ was found in $67 \%$ of the patients with $\mathrm{ICH}$, against $42 \%$ of the patients with $\mathrm{CI}$, but a diastolic blood pressure of more than $90 \mathrm{~mm} \mathrm{Hg}$ was almost equally common in both groups (59\% of the patients with $\mathrm{ICH}$ and $49 \%$ in patients with $\mathrm{CI}$ ). The severity of the hemiparesis was similar in the two patient groups. The mean blood glucose level and the percentages of patients with serum glucose values of $8 \mathrm{mmol} /$ 1 or more on admission did not differ between the two patient groups.

All surviving patients with $\mathrm{ICH}$ or $\mathrm{CI}$ had a neurologic evaluation at three, 14 and 30 days, and at four, eight and 12 months. In the univariate analysis, the proportion of deaths or a good outcome in patients with a certain characteristic (for instance severe hemiparesis) was compared with that in patients without the characteristic employing relative risk. The $95 \%$ confidence interval was used to describe the precision of the relative risk. Variables selected from univariate analysis were sequentially entered into a logistic model until no remaining candidate variable met a significance level of $p=0.05$. The odds ratio (OR) resulting from the logistic model may be interpreted as relative risks. If a patient has more than one of the characteristics selected in the model, the risk of death relative to that in a patient without those characteristics is obtained by multiplying the odds ratios of those characteristics. The $\chi$ test was used where appropriate.

\section{Results}

Baseline characteristics of the patients with ICH are presented in table 1. The ICH occurred on the right side in 78 and on the left side in 79 patients. A lobar haematoma occurred in 60 patients and a haematoma in the basal ganglia in 97 patients. No significant difference in age, haematoma volume, history of hypertension, or use of oral anticoagulants existed between patients with a lobar or basal ganglia haematoma. Headache on admission was significantly more common in patients with lobar haematoma ( $52 \%)$ than in patients with basal ganglia haematoma $(28 \%)$ $(p<0.01)$. Early seizures occurred in $13(8 \%)$ patients, in nine $(15 \%)$ with a lobar haematoma versus four (4\%) with a basal ganglia haematoma $(p<0.05)$. Vomiting on admission $(n=63)$ occurred equally in both groups. Rupture of the haematoma in the ventricular system occurred significantly more often in patients with a basal ganglia haematoma $(54 \%)$ than in lobar haematomas (35\%) $(p<0.05)$. In patients with lobar haematomas the fourth ventricle was never completely filled with blood. The 27 patients who were on oral anticoagulants at the time of the event had a

Table 1 The occurrence of two day and third day to one year mortality in relation to several clinical characteristics at the time of the bleeding in 157 patients with intracerebral haemorrhage

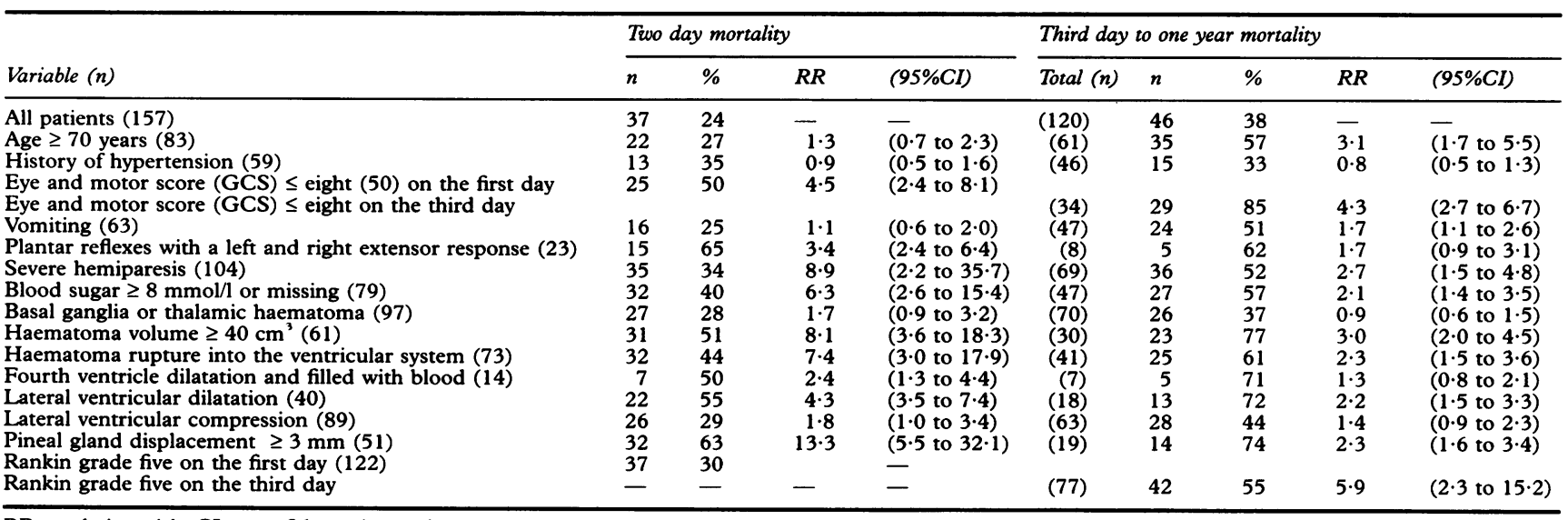

$\mathrm{RR}=$ relative risk; $\mathrm{CI}=$ confidence interval 
mean haematoma volume of $51 \mathrm{~cm}^{3}$, versus $33 \mathrm{~cm}^{3}$ in patients with $\mathrm{ICH}$ not receiving anticoagulants $(p=0.058)$.

Death from transtentorial herniation within two days occurred in $37(24 \%)$ of the 157 patients with ICH, 32 of whom died within one day. The mean age of these 37 patients was 70 years (range 48-89). A history of hypertension or the use of oral anticoagulants was equally common in these 37 patients as in the 120 patients with $\mathrm{ICH}$ who survived the first two days. All 37 patients who died early had been completely dependent (Rankin grade five) on admission. The GCS (where the maximum is 10) the score was nine or 10 in 12 patients who died early and eight or less in the remaining 25 patients. Fifteen of the 19 patients $(79 \%)$ in whom the blood glucose level was not determined died within two days. In a multivariate analysis, the risk of death within two days was determined by displacement of the pineal gland of $3 \mathrm{~mm}$ or more $(\mathrm{OR}=14, \mathrm{p}<0.001)$, blood glucose level on admission of $8 \mathrm{mmol} / \mathrm{l}$ or more (including patients with missing values) ( $O R=5.5$, $p=0.01$ ), eye and motor score of eight or less on the GCS (OR $=3.9, p=0.022)$ and haematoma volume of $40 \mathrm{~cm}^{3}$ or more $(\mathrm{OR}=3 \cdot 6$, $p=0.037)$. In the subgroup of patients with Rankin grade five on admission $(n=122)$, the two day mortality was determined by the same characteristics. Exclusion of the 19 patients with a blood glucose level which was not determined yielded essentially the same model. The 30 day case fatality rate in all patients with ICH was $43 \%$ (68 of the 157 patients).

After 12 months, 83 of the 157 patients (53\%) with ICH had died. The death rate at one year did not differ between patients with or without anticoagulants ( 15 of 27 [56\%] and 68 of 130 [52\%], respectively). The one year mortality in the two groups with lobar or basal ganglia haematoma was also similar, $50 \%$ and

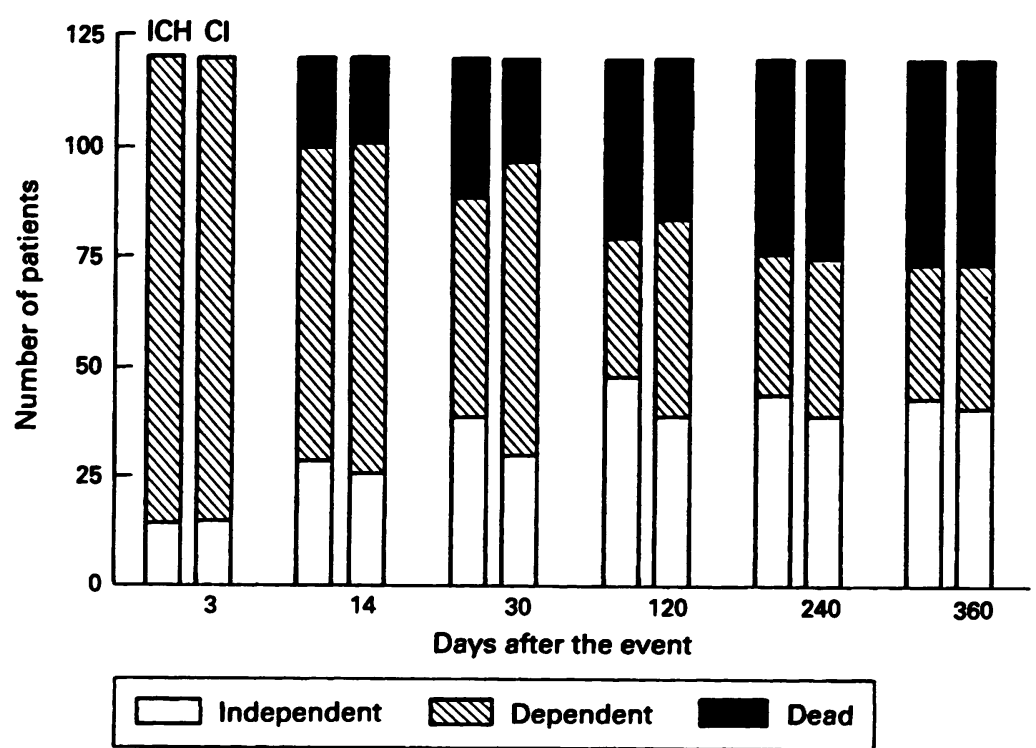

Figure The change in the contracted Rankin scale (functionally independent [Rankin grades zero to two] or dependent [Rankin grades three to five]) from the third day to one year in the 120 patients with intracerebral haemorrhage (ICH) (left bars) and cerebral infarction (CI) (right bars).
Table 2 Main causes of death in the 120 patients with intracerebral haemorrhage who survived the first two days and their matched controls with cerebral infarction

\begin{tabular}{lrrrr}
\hline Main cause of death & \multicolumn{1}{c}{$I C H$} & $\%$ & \multicolumn{1}{c}{$C I$} & $\%$ \\
\hline Infection & 16 & 34 & 19 & 41 \\
Tentorial herniation & 11 & 24 & 8 & 17 \\
Ischaemic heart disease & 5 & 11 & 7 & 15 \\
Recurrent stroke & 4 & 9 & 2 & 5 \\
Pulmonary embolism & 3 & 7 & 3 & 7 \\
Miscellaneous & 7 & 15 & 7 & 15 \\
Total & 46 & 100 & 46 & 100 \\
\hline
\end{tabular}

ICH = intracerebral haemorrhage; $\mathrm{CI}=$ cerebral infarction

$55 \%$, respectively. The occurrence of early seizures did not influence outcome. In the multivariate analysis of the risk factors for death between the third day and one year after the event, the predictors were age of 70 years or more $(O R=6.1, p<0.001)$ and severe handicap (Rankin grade five) on the third day $(\mathrm{OR}=9.5, \mathrm{p}<0.001)$. Sex, history of hypertension, systolic and diastolic blood pressure, pulse pressure, the side of the stroke, changes in Rankin grade, and eye and motor scores between admission and the third day, did not independently contribute to the model, nor did the variables not mentioned above but listed in table 1. Functional independence at one year (43 patients) was determined by an age of less than $70(p<0.001)$, eye and motor score of nine or 10 on the GCS on the third day $(p<0.001)$, and Rankin grade four or less on the third day $(p=0.002)$.

The outcome after 12 months in the 120 patients with $\mathrm{ICH}$ who were still alive after two days did not differ from that in the 120 matched controls with CI. Forty six patients in both groups had died (fig). After adjustment for differences in baseline characteristics, the mortality in the two patient groups was also similar. Recurrent stroke occurred in four patients with ICH (all fatal) and in three patients with CI (two fatal). Sixteen patients (six with $\mathrm{ICH}$ and 10 with $\mathrm{CI}$ ) died between the fifth and twelfth month; this number significantly exceeded the expected total number of deaths (five) in an age matched and sex matched group from the general population. Twelve months after the stroke, 43 patients with ICH and 41 patients with $\mathrm{CI}$ (both about one third of the original group) were functionally independent. The distribution of the Rankin grades was also the same at the different intervals within the 12 month follow up period (fig). The main causes of death after the second day were similarly distributed (table 2). Altogether $45 \%$ of the deaths between two days and one year were caused by complications of immobility, particularly infections and pulmonary embolism.

Urinary and faecal incontinence after two weeks was a prognostic indicator for survival at one year in patients with $\mathrm{ICH}$ as well as with CI: 41 of the 90 patients $(46 \%)$ with incontinence had died at 12 months, versus 12 out of $105(11 \%)$ without incontinence (relative risk $4 \cdot 0,95 \%$ confidence interval $2 \cdot 2$ to $7 \cdot 1$ ). For six patients no information about continence was available; none of them died. 


\section{Discussion}

The initial mortality after ICH is high and occurs mostly within one or two days. After that time, the chance of recovery in patients with ICH is similar to that in patients with ischaemic stroke. This means that once the danger of cerebral herniation has passed, it is the extent and not the cause of the structural brain damage that determines the prognosis.

The proportion of patients with $\mathrm{ICH}$ who died within the first two days (24\%) corresponds with that reported in other studies. ${ }^{11}$ The independent indicators for early death in our study were: pineal gland displacement, a high blood glucose level on admission ( $8 \mathrm{mmol} / \mathrm{l}$ or more), the eye and motor score on the GCS, and the haematoma volume. Some previous studies with multivariate analysis in patients with $\mathrm{ICH}$ found other indicators for prognosis, but these determined outcome on discharge, ${ }^{4}$ at $30^{6911}$ or 60 days, $^{7}$ or at six months ${ }^{8}$ after the haemorrhage. The variables selected in those cases were rupture of the haematoma in the ventricular system, ${ }^{9}$ hypertension and pulse pressure. ${ }^{7}$ The level of consciousness $^{467811}$ and haematoma volume or size, ${ }^{489}$ have also been identified as prognostic indicators, as in our study. The importance of pineal gland displacement confirms that the space the haematoma occupies is an important determinant of early outcome. A relation between pineal gland displacement and impairment of consciousness has been identified in previous studies, ${ }^{1920}$ but we found these two factors independently predicted mortality within two days. Hyperglycaemia on admission as an indicator of a poor prognosis in patients with $\mathrm{ICH}$ has been reported before. $^{21}$ The hyperglycaemia is probably not directly harmful to the brain but reflects stress relating to stroke severity. ${ }^{21}$ The strong relationship with early death is only partly explained by inclusion of the 19 patients in whom no glucose level was available, usually because their clinical condition was judged too poor to justify the collection of a blood sample.

The death rate of $53 \%$ one year after the event in patients with $\mathrm{ICH}$ is much higher than that in another study (34\%), ${ }^{22}$ but only $32 \%$ of the patients in that study were admitted to hospital within 24 hours, against $96 \%$ in ours. The very short delay between ICH onset and hospital admission in our study, meant that even moribund patients still reached the hospital alive. It is possible, but not likely, that milder cases with ICH have not been referred, as the 30 day mortality in our study (43\%) was only slightly higher than that in a recent population based study from Italy $(38 \%),{ }^{14}$ and lower than that in the Oxfordshire community study $(52 \%){ }^{5}$ We found severe handicap (Rankin grade five) on the third day and not the level of consciousness as prognostic indicator for mortality at one year; of the 77 patients with severe handicap on day three, 38 had a normal level of consciousness. Twenty seven per cent of all patients $(n=43)$ with $\mathrm{ICH}$ reached functional independence at one year, which is in accordance with a previous and prospective community study. ${ }^{5}$ Age and level of consciousness as prognostic indicator of good clinical outcome 12 months after ICH in our study confirmed the finding in a former study without multivariate analysis. ${ }^{22}$ One study with multivariate analysis found as independent predictors of satisfactory outcome at six months: age, haemorrhage size, rupture of the haematoma in the ventricular system, limb weakness and communication disorders. ${ }^{9}$ Our results also confirm previous studies about incontinence in patients two weeks after stroke as a predictive factor for one year mortality. $^{23} 24$

The patients with ICH who survived the first two days had a similar outcome as patients with CI who were matched according to Rankin grade, age and level of consciousness. This similarity applies to the proportion of dependent patients during follow up as well as to the number of patients who died and the causes of death. Previous studies found differences in 30 day mortality rates in favour of patients with ICH from 28 to $46 \%$ (30 day mortality rate of 38 to $66 \%$ in patients with ICH versus 10 to $20 \%$ in patients with CI). ${ }^{15111214}$ Between the thirtieth day and one year, roughly the same mortality rate $(10-16 \%)$ has been reported for patients with ICH or CI. ${ }^{151112}$ In only two studies, ${ }^{514} \mathrm{CT}$ confirmation was never ${ }^{12}$ or only rarely ${ }^{11}$ available. After the high initial death rate in patients with $\mathrm{ICH}$ in the first weeks, these studies found no differences in late mortality rate between non-matched groups of patients with ICH or CI. ${ }^{511214} \mathrm{~A}$ previous prospective population study with multivariate analysis also identified age and severity of stroke (minor stroke versus major stroke) as prognostic indicators for survival one year after the event, and not the subtype of stroke (ICH or CI). ${ }^{15}$ The same study did not find an excess in mortality between five and 12 months compared with the general population, ${ }^{15}$ in contrast to our study. The excess mortality in our study is probably the result of our method of matching, by which we have purposely excluded milder cases of ischaemic stroke.

We have insufficient reason to suppose that the omission of surgical evacuation in our patients with ICH negatively influenced their outcome, as the benefits of this mode of treatment are not established. ${ }^{25-27}$ In a few patients, or operation was considered because of progressive deterioration before the stage of irreversible brain stem dysfunction, but they improved spontaneously. More trials of surgical treatment are necessary; the prognostic factors we found in this study may help in identifying those patients who could gain most from treatment.

We are grateful to M J J Buscher and C P M C Claassens for collecting data and to José Schmitz and Liza Franke for secretarial assistance.

1 Silver FL, Norris JW, Lewis AJ, Hachinski VC. Early mortality following stroke: A prospective review. Stroke $1984 ; 15: 492-6$.

2 Franke CL, de Jonge J, van Swieten JC, Op de Coul AAW, van Gijn J. Intracerebral haematomas during anticoagulant treatment. Stroke 1990;21:726-30. 
3 Douglas MA, Haerer AF. Long-term prognosis of hypertensive intracerebral haemorrhage. Stroke 1982;13: 488-91.

4 Portenoy RK, Lipton RB, Berger AR, Lesser ML, Lantos G Intracerebral haemorrhage: a model for the prediction of outcome. $\mathcal{F}$ Neurol Neurosurg Psychiatry 1987;50:976-9.

5 Bamford J, Sandercock P, Dennis M, Burn J, Warlow C. A prospective study of acute cerebrovascular disease in the community: the Oxfordshire community stroke project 1981-86, 2. Incidence, case fatality rates and overall outcome at one year of cerebral infarction, primary intracerebral and subarachnoid haemorrhage. $f$ Neurol Neurosurg Psychiatry 1990;53:16-22.

6 Tuhrim S, Dambrosia JM, Price TR, Mohr JP, Wolf PH, Heyman A, Kase CS. Prediction of intracerebral haemorrhage survival. Ann Neurol 1988;24:258-63.

7 Senant J, Samson M, Proust B, Szeibert J, Onnient Y. Approche multi-factorielle du pronostic vital des hèmaomes intracérébrauxspontanés. (In French) Rev Neurol Paris) $1988 \cdot 144: 279-83$.

8 Dixon AA, Holness RO, Howes WJ, Garner JB. Spontaneous intracerebral haemorrhage: an analysis of factor

affecting prognosis. Can $\mathcal{F}$ Neurol Sci 1985;12:267-71.

Daveral P, Castel JP, Dartigues JF, Orgogozo JM. Death and functional outcome after spontaneous intracerebral haemorrhage. A prospective study of 166 cases using multivariate analysis. Stroke 1991;22:1-6.

10 White OB, Norris JW, Hachinski VC, Lewis A. Death in early stroke, causes and mechanisms. Letter to the Editor Stroke $1979 ; 10: 743$.

11 Chambers BR, Norris JW, Shurvell BL, Hachinski VC. Prognosis of acute stroke. Neurology 1987;37:221-5.

12 Abu-Zeid HAH, Choi NW, Hsu PH, Maini KK. Prognostic factors in the survival of 1,484 stroke cases observed for 30 to 48 months. I. Diagnostic types and descriptive 30 to 48 months. I. Diagnostic types

13 Bonita R, Ford MA, Stewart AW. Predicting survival after stroke: A three-year follow-up. Stroke 1988;19:669-73.

14 Ricci S, Celani MG, La Rosa F, Vitali R, Duca E, et al. SEPIVAC: a community-based study of stroke incidence in Umbria, Italy. $f$ Neurol Neurosurg Psychiatry 1991;54:695-8.

15 Westling B, Norrving B, Thorngren M. Survival followin stroke. A prospective population-based study of 438 hospitalized cases with prediction according to subtype, severity and age. Acta Neurol Scand 1990;81:457-63.

16 Van Swieten JC, Koudstaal PJ, Visser MC, Schouten HJA, van Gijn J. Interobserver agreements for the assessment of handicap in stroke patients. Stroke 1988;19:604-7.

17 Bamford JM, Sandercock PAG, Warlow CP, Slattery J. Interobserver agreement for the assessment of handicap in stroke patients (letter). Stroke 1989;20:828.

18 Franke CL, Versteege CWM, van Gijn J. The best fit method, a simple way for measuring the volume of an intracerebral haematoma. Neuroradiology 1988;30:73-5.

19 Ropper AH. Lateral displacement of the brain and level of consciousness in patients with an acute hemispheral mass. $N$ Engl f Med 1986;314:953-8.

20 Ropper AH, Gress DR. Computerized tomography and clinical features of large cerebral haemorrhages. Cerebrovasc Dis 1991;1:38-42.

21 Woo J, Lam CWK, Kay R, Wong AHY, Teoh R, Nicholls MG. The influence of hyperglycemia and diabetes mellitus on immediate and 3-month morbidity and mortality after acute stroke. Arch Neurol 1990;47:1174-7.

22 Fieschi C, Carolei A, Fiorelli M, Argentino C, Bazzao I Fazio C, Salvetti M, Bastionello S. Changing prognosis of primary intracerebral haemorrhage: results of a clinical and computed tomographic follow-up study of 104 patients. Stroke 1988;19:192-5.

23 Wade DT, Hewer RL. Functional abilities after stroke: measurement, natural history and prognosis. 7 Neurol Neurosurg Psychiatry 1987;50:177-82.

24 Henley S, Pettit S, Todd-Pokropek A, Tupper A. Who goes home? Predictive factors in stroke recovery. $f$ Neurol Neurosurg Psychiatry $1985 ; 48$ : 1-6.

25 Juvela S, Heiskanen O, Poranen A, Valtonen S, Kuurne T, et al. The treatment of spontaneous intracerebral hemoral. The treatment of spontaneous intracerebral hemorrhage. A prospective randomized trial of surgical

26 Auer LM, Deinsberger W, Niederkorn K, Gell G, Kleinert $\mathrm{R}$, et al. Endoscopic surgery versus medical treatment for spontaneous intracerebral hematoma: a randomized study. F Neurosurg 1989;70:530-5.

27 Batjer HH, Reisch JS, Allen BC, Plaizier LJ, Su CJ. Failure of surgery to improve outcome in hypertensive putaminal hemorrhage. Arch Neurol 1990;47:1 103-6. 